\title{
Properties of Residual Marine Fuel Produced by Thermolysis from Polypropylene Waste
}

\author{
Rasa BUTKUTE் ${ }^{1,2}$, Linas MIKNIUS ${ }^{1 *}$ \\ ${ }^{1}$ Kaunas University of Technology, Radvilenu Rd. 19, LT-50254 Kaunas, Lithuania \\ ${ }^{2}$ Klaipèda University, Bijūnu St. 17, LT-91225 Klaipèda, Lithuania \\ crossref http://dx.doi.org/10.5755/j01.mm.21.2.6105
}

Received 02 January 2014; accepted 05 April 2014

\begin{abstract}
Thermal degradation of waste plastics with the aim of producing liquid fuel is one of the alternative solutions to landfill disposal or incineration. The paper describes thermal conversion of polypropylene waste and analysis of produced liquid fuel that would satisfy ISO 8217-2012 requirements for a residual marine fuel. Single pass batch thermolysis processes were conducted at different own vapour pressures $(20-80 \mathrm{bar})$ that determined process temperature, residence time of intermediates what resulted in different yields of the liquid product. The obtained products were stabilized by rectification to achieve required standard flash point. Gas chromatography and ${ }^{1} \mathrm{H}$ NMR spectrometry show aliphatic nature of the liquid product where majority of the compounds are isoalkanes and isoalkenes. Only lightest fractions boiling up to a temperature of $72^{\circ} \mathrm{C}$ have significant amount of $n$-pentane. Distribution of aromatic hydrocarbons is not even along the boiling range. The fractions boiling at a temperature of $128^{\circ} \mathrm{C}$ and $160^{\circ} \mathrm{C}$ have the highest content of monocyclic arenes $-3.16 \%$ and $4.09 \%$ respectively. The obtained final liquid residual product meets all but one requirements of ISO 8217-2012 for residual marine fuels.

Keywords: residual marine fuels, thermolysis, polypropylene waste.
\end{abstract}

\section{INTRODUCTION}

Accumulating non-biodegradable organic waste is one of the threats to an environment that still increasing in many industrialized countries for the past few decades. The waste plastic management issue could be solved if economic, political, technological, energetic, material and environmental dimensions would be considered [1-5]. In EU overall production of plastics exceeds 50 million tons annually and polypropylene share is about $19 \%$ of the amount [6]. Lithuania in polypropylene import-export balance as consumption has over 10,000 tons per year [7]. A certain amount of the production can be considered as a potential waste. The recycling of material, the use of landfills or the incineration are among many ways of waste plastics processing. One of the desired methods of plastic waste management is primary recycling, i.e., reuse of products in their original structure [8]. However, this is possible for some wastes and there is also an obvious limit on the number of cycles for each material. In secondary recycling, plastics are mixed, ground, re-melted and reformed in order to produce lower value products. In tertiary recycling, polymer wastes are decomposed into raw material or into chemical feedstock or fuel. In quaternary recycling, energy is recovered through burning $[9,10]$. Among the various methods of waste plastics recycling, the tertiary utilization has attracted much attention from the viewpoint of the energy resource. Thermolysis process, conducted at high temperature and non-oxidative environment is considered one of the most promising because waste plastics can be upgraded into valuable chemicals and various states and purpose fuels. Thermolysis

\footnotetext{
${ }^{*}$ Corresponding author. Tel.: +370-612-23512; fax.: +370-37-300152.
} E-mail address: linas.miknius@ktu.lt (L. Miknius) can be conducted with or without a catalyst. The advantage of catalytic process is a lower temperature as well as faster degradation of a feedstock and a narrower fractional composition of the products. However, economic efficiency still remains a problem because commercial catalysts generally are expensive, have a relatively short life cycle and typically non-regenerable in the thermolysis process [11-20]. If such material has energetic value, i. e., high content of carbon and hydrogen and low content of heteroatoms, it becomes a valuable feedstock for production of fuels. Conventional fuels as automotive gasoline, jet and diesel fuel are produced from petroleum - most attractive and easily refined feedstock. The products, however, have to meet a number of strict standard requirements specified in EN 228, EN 590 etc. Conversion of organic waste to the fuels becomes a challenge since the whole refining technology must be supplemented with an initial destruction process, moreover feedstock sorting and logistic problems must be solved too. As an option, a production of the lower quality demanded fuels could be considered [21-28]. Large sea ships in low speed engines burn poor quality residual fuels, such as long residues or fuel oils and smaller ones consume distillate fuel, similar to a diesel fuel but lower quality. ISO 8217-2012 standard specifies 16 quality parameters for 11 grades of residual marine fuels [29]. Port of Klaipeda for the ships exploits ISO-F-RME 180 and ISO-F-RMG 380 grade fuels [30]. The main difference between the grades is viscosity and for the heavier grade the higher content of specific impurities is allowed. A feedstock selection for the production is a strategic task, because the yield of a liquid product and key properties - elemental composition (sulfur, nitrogen, chlorine compounds and metals), combustion quality, carbon residue, pour point are highly dependent on a chemical composition and a structure of the polymeric feed being destructed. Among organic waste materials 
polypropylene shows itself as the most attractive feedstock because its pure hydrocarbon nature and branched chemical structure predicts good energetic, viscosity and low temperature properties of the final product. According to ISO 8217, all marine fuels fall either into distillate or residual categories. Distillate marine fuel production from polypropylene waste was presented by Butkute [31]. This work dwells upon investigation of residual marine fuels produced from opaque and transparent polypropylene waste.

\section{EXPERIMENTAL DETAILS}

Thermal depolymerization of the feedstock was conducted in a $3 \mathrm{dm}^{3}$ capacity batch reactor (Fig. 1).

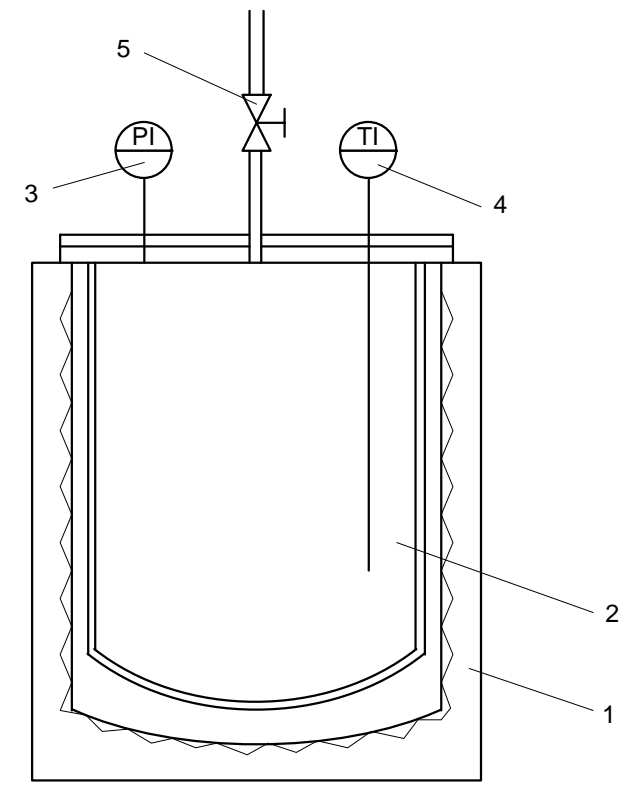

Fig. 1. Thermolysis reactor: 1 - muffle furnace; 2 - reactor; 3 - pressure transducer; 4 - thermocouple; 5 - vent valve

The reactor is pressurized steel vessel equipped with a pressure transducer, a thermowell for a thermocouple and a manual control valve for gaseous products release. The reactor is loaded with $1 \mathrm{~kg}$ of feedstock, purged with inert nitrogen gas, sealed with aluminum gasket and closed with a steel lid fastened with bolts via flanges. The device for the process is placed in a $3 \mathrm{~kW}$ electrically powered muffle furnace.

Liquefaction of polymeric feedstock by solely batch thermal decomposition process is rather impossible for along with liquid product formation inevitable gas formation reactions run as well. The thermolysis processes, therefore, were conducted by heating the feedstock until the pressure in the reactor reached 20, 40, 60 and 80 bar (gauge). After cooling down the system the gaseous products were released and measured for a mass balance purpose. The liquid products were removed after opening the lid and stabilized in a sense of volatility by distilling off the lightest components in order to meet required flash point for marine residual fuels.

In LST ISO 8217:2012 specification for marine residual fuels described quality parameters were measured by applying standard methods of investigation: kinematic viscosity - LST EN ISO 3104; density - LST EN ISO 3675; Calculated Carbon Aromaticity Index (CCAI) -
Calculated, by Shell; Sulfur content - LST EN ISO 8754; Flash point by open cup method - LST EN ISO 2719; Hydrogen sulfide content - IP 570; Acid number - ASTM D 664; Total sediment aged - ISO 10307-2; Carbon residue: micro method - LST EN ISO 10370; Pour point LST EN LST ISO 3016; Water content - ISO 3733; Ash content - LST EN ISO 6245; Vanadium, Sodium Aluminum, Silicon, Calcium, Zinc, and Phosphorus content - IP 501 [29].

Stabilization of the liquid product was performed by conventional distillation unit equipped with rectifying column.

Analysis of liquid fraction chemical composition was performed on gas chromatograph-mass spectrometer Shimadzu "GCMC-QP2010 Ultra“. Rtx-1 equipped with Restek PONA Capillary Column $150 \mathrm{~m}, 0.25 \mathrm{~mm}$ ID, $0.5 \mu$. ${ }^{1} \mathrm{H}$ NMR spectrum of the liquid product was recorded at $400 \mathrm{MHz}$ on a Bruker Avance III spectrometer.

The changes of parameters during thermolysis process are depicted in Fig. 2. The shape of the curves of each batch process slightly differ but the character is the same.

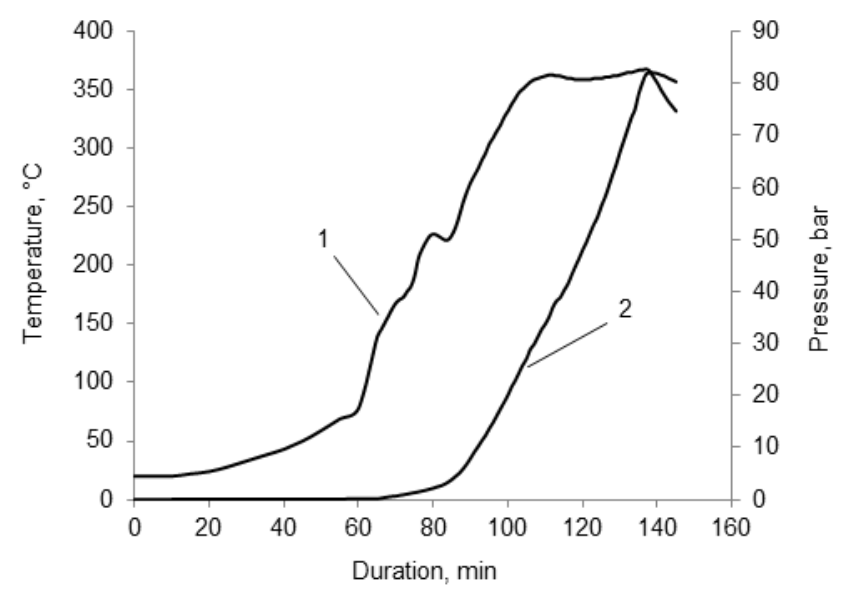

Fig. 2. Thermolysis process parameters change: 1 - temperature; 2 - pressure

A non-uniform pattern of a temperature curve indicates physical and chemical processes taking place during the thermolysis. Up to $80 \mathrm{~min}$ it is observed changes in a solid state and melting of the feedstock, which are accompanied by energy consumption/release. The negligible pressure increase in this stage of the process is solely on thermal expansion of initially trapped gas in the reactor. When the temperature exceeds $350^{\circ} \mathrm{C}$, it is observed a severe chemical decomposition of the feed. The cleavage endothermic reactions consumes so much heat (about $3 \mathrm{~kJ} /(\mathrm{kg} \cdot \mathrm{s})$ ) that a temperature does not rise until the end of the process, i.e., until pressure reaches the final point - 80 bar. The lightest gaseous and liquid products of decomposition being vaporized give a rapid pressure rise during 90-130 min of the process. Heating of the reactor is shut off as one of the planned pressure values is reached.

\section{RESULTS}

Thermolysis of opaque polypropylene feedstock independently to process parameters gave the hardly separable suspensions, unsuitable to use as a fuel due to extremely high ash and sediment content. Opaque polypro- 
pylene produces add mineral fillers to enhance certain properties and reduce cost of a product. Elemental analysis of the thermolysis feedstock shows high content of calcium in the opaque polypropylene. The rest heteroelements are in the range between $0.633 \mathrm{mg} / \mathrm{kg}$ and $0.3033 \%$ (Table 1). The large gap (over $8 \%$ ) of unidentified elements of opaque polypropylene must belong to oxygen most probably from calcium carbonate used as a polymer filler.

Table 1. Elemental composition (mass \%) of a feedstock of thermolysis

\begin{tabular}{|l|c|c|}
\hline \multirow{2}{*}{ Element } & \multicolumn{2}{|c|}{ Polypropylene } \\
\cline { 2 - 3 } & opaque & translucent \\
\hline Carbon & 73.82 & 81.54 \\
\hline Hydrogen & 12.04 & 16.21 \\
\hline Sulfur & $2.416 \cdot 10^{-3}$ & 0.054 \\
\hline Vanadium & $6.33 \cdot 10^{-5}$ & $6.7 \cdot 10^{-5}$ \\
\hline Sodium & 0.0566 & 0.0234 \\
\hline Aluminum & 0.2549 & 0.414 \\
\hline Silicon & 0.17391 & 0.457 \\
\hline Calcium & 6.240 & $2.75 \cdot 10^{-3}$ \\
\hline Zinc & 0.0582 & 0.0463 \\
\hline Phosphorus & 0.030 & 0.2762 \\
\hline Nickel & $5.6 \cdot 10^{-3}$ & $5.12 \cdot 10^{-3}$ \\
\hline Iron & 0.3033 & 0.1673 \\
\hline Total & 92.98 & 99.20 \\
\hline
\end{tabular}

During one pass through batch thermolysis the full conversion was not observed as in a case of distillative thermolysis process [31], where all obtained products are chemically transformed feedstock. There some unreacted feedstock was left as easily separable crystals. As the results show (Table 2), the conversion is considerably dependent on a process severity, i. e., combined influence of duration and temperature, which directly depends on a process pressure (Fig. 2).

Table 2. The yield of thermolysis products (mass \%)

\begin{tabular}{|l|c|c|c|}
\hline \multirow{2}{*}{ Product } & \multicolumn{3}{|c|}{ Process pressure, bar } \\
\cline { 2 - 4 } & 40 & 60 & 80 \\
\hline Gaseous & 8.4 & 13.1 & 18.2 \\
\hline Liquid & 26.4 & 38.7 & 40.1 \\
\hline Solid & 1.7 & 2.1 & 2.6 \\
\hline Unconverted & 63.5 & 46.1 & 39.1 \\
\hline Conversion & 0.365 & 0.539 & 0.609 \\
\hline
\end{tabular}

Under the own vapour pressure of 20 bar, the temperature was reached $330^{\circ} \mathrm{C}$ that appeared too low to break covalent bonds in polypropylene. The results show (Table 2) that increasing severity of the process enhances conversion of the feedstock, however the influence to the target liquid product yield is not the same. As a process pressure rose from 40 to $60 \mathrm{bar}$, increased conversion raised mainly the yield of a liquid product. When the process is conducted at more elevated pressure (80 bar), the increase of liquid product amount is rather small compared to gas yield increase. The reason of such distribution is secondary thermal decomposition reactions of the liquid product that resides in the reaction zone long enough to cleave into the gases. The overall Le Chatelier's principle as expected regarding pressure in the reactor and the gas yield was not observed. The yield of the solid product increased with a process pressure (Table 2). The solid residue is composed not only of heteroatom compounds but products of secondary polycondensation reactions have their share too. The longer the residence time at elevated temperature, the more coke is formed.

A detail analysis of the liquid thermolysis product requires considerable amount of a sample as the most testing methods are specimen destructive. Moreover, a flash point of the liquid product depends only on the initial boiling point of the sample. Thus, the analysis of a liquid product was carried out on the combined product of the three thermolysis experiments.

A standard requirement for a flash point minimal value of residual marine fuels is $60^{\circ} \mathrm{C}$. The precise way to reach it is to stabilize the liquid thermolysis product removing the lightest compounds by means of rectification. Since a repeatability of a flash point of complex mixtures is in the range of few degrees, the several distillations and measurements were made. The results (Fig. 3) show that required flash point for a marine residual fuel only can be reached if compounds lighter than having boiling point of $170^{\circ} \mathrm{C}$ would be distilled off. The separation of the light fraction reduces the yield of the product by $40 \%$.

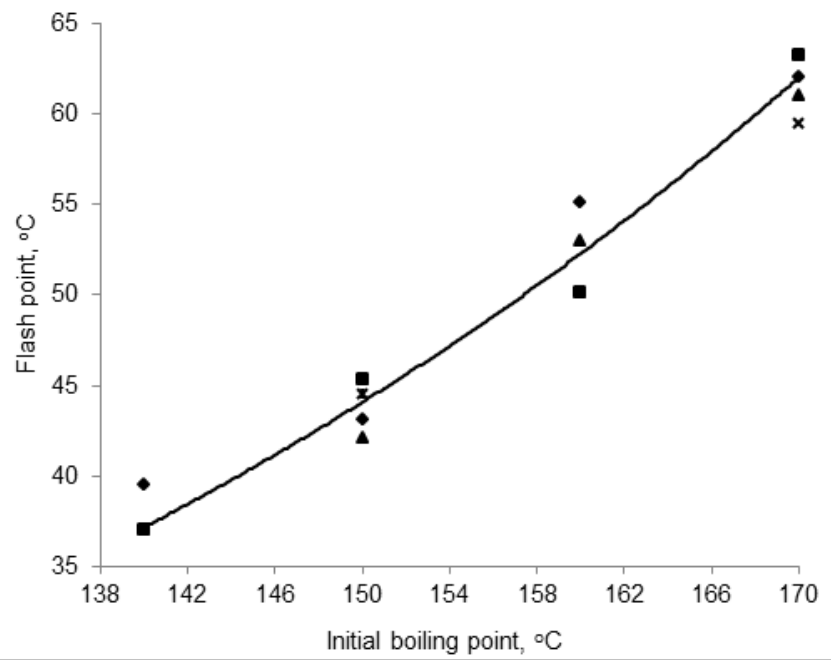

Fig. 3. Flash point dependence on initial boiling point of liquid thermolysis product

Gas chromatography analysis of the light ends (Table 3) discloses exceptionally aliphatic composition. Aromatic hydrocarbons share in the mixture do not reach $1 \%$. From over 150 of identified hydrocarbons, only 26 are depicted in Table 3, which content in either of four samples is greater than $1 \%$. In the lightest specimens (initial boiling point (IBP) $\left(30^{\circ} \mathrm{C}\right)$ and $72^{\circ} \mathrm{C}$ ) in the greatest amount (up to $36 \%$ ) $n$-pentane was observed, which appeared the only hydrocarbon of a linear structure detected in a considerable amount in the complex mixture. The other dominant hydrocarbons in the two specimens appeared six-carbon branched chain compounds: 2-methylpentane and 2-methyl-1-pentene. As a boiling point increases, the molecular mass of the dominant compounds increases too. Nearly half of the amount of the specimens that boil at a temperature of $128^{\circ} \mathrm{C}$ and $160^{\circ} \mathrm{C}$ is made of 2,4-dimethyl-1-heptene, 4-methylheptane and 1,3,5-trimethylcyclo-hexane. There is no significant amount of linear hydrocarbons. Isoalkanes, isoalkenes and 
substituted naphthenes predominate in the mixtures. Such a composition is determined by the chemical structure of the thermolyzed feedstock. Nearly half of the amount in any specimen compose unsaturated (alkenes, alkadienes, cycloalkenes) hydrocarbons which are very susceptible for secondary chemical reactions. Such reactions as addition, cleavage and cyclization proceed fast in comparison with aromatization reactions which run over a few stages, therefore, aromaticity of thermolysis products are so low.

Proton NMR spectrum (Fig. 4) of stabilized liquid product of thermolysis shows no detection of arenes (chemical shifts in the range of $(6.40-8.30) \mathrm{ppm})$ in the residual marine fuel being produced. In the range of $(2.00-4.00)$ ppm lay signals of all protons that are connected to carbon atoms that are located in alpha position in respect of aromatic ring. These protons make only $1 \%$ of the whole protons of the product. The reason the aromatic hydrogen atoms were not detected in the spectrum - the aromatic compounds left in the residue are highly substituted with alkyl groups, which contain more protons than aromatic rings themselves, e.g., mesitylene (Table 3). The chemical shifts area (1.05-2.00) ppm represents protons of methylene and methyne groups bonded to carbon atoms that are farther than alpha position to an aromatic ring. In our case it means all methylene and methyne protons. The area of chemical shifts in the range of $(0.5-1.05) \mathrm{ppm}$ reflects methyl groups that are connected anywhere but aromatic ring. In this case practically any methyl group gives a peak in this range. The ${ }^{1} \mathrm{H}$ NMR analysis (Fig. 4) of the product shows a high degree of branching when substituents of main hydro- carbon chains are predominantly methyl groups (methyl protons ratio to the rest ones relates as 49.27:49.86).

The obtained liquid residual product meets all but one standard (ISO 8217-2012) requirements for residual marine fuels (Table 4). Exceptionally low kinematic viscosity eliminates preheating procedure typically required during exploitation of the fuel.

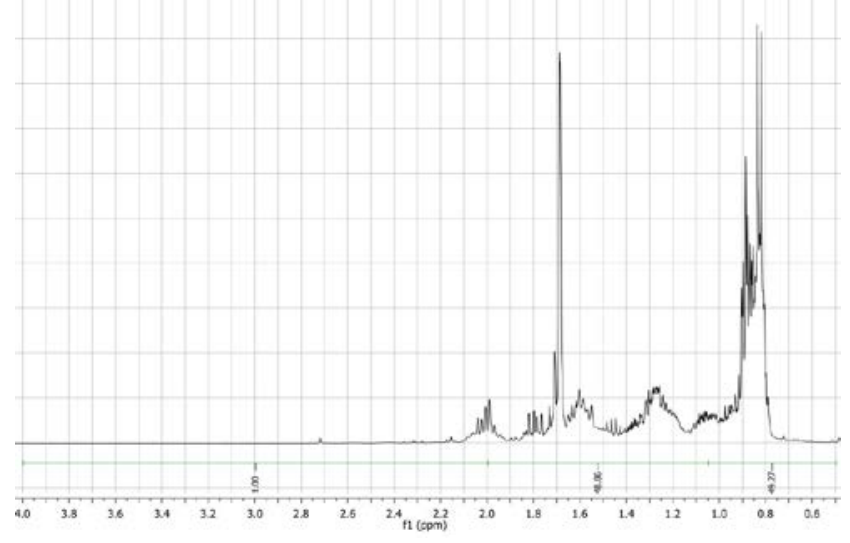

Fig. 4. ${ }^{1} \mathrm{H}$ NMR spectrum of liquid residual thermolysis product

For determination of ignition quality of residual fuels presently most accepted method is CCAI which lower values indicates shorter ignition delay and better ignition quality. Generally CCAI values lower than 850 never induce ignition problems. The feedstock inherently possess no sulfur, however, traces of sulfur compounds in the waste derived fuel are detectable.

Table 3. Chemical composition (\%) of light end fractions of the target product

\begin{tabular}{|c|c|c|c|c|c|}
\hline \multirow{2}{*}{ Compound } & \multirow{2}{*}{$\begin{array}{c}\text { Number of } \\
\text { carbon atoms in } \\
\text { compound chain }\end{array}$} & \multicolumn{4}{|c|}{ Light end fraction boiling point } \\
\hline & & $\operatorname{IBP}\left(30^{\circ} \mathrm{C}\right)$ & $72^{\circ} \mathrm{C}$ & $128^{\circ} \mathrm{C}$ & $160^{\circ} \mathrm{C}$ \\
\hline 2-Methylbutane & 5 & 0.71 & 1.05 & 0.06 & - \\
\hline$n$-Pentane & 5 & 26.60 & 36.09 & 2.89 & 0.12 \\
\hline 2-Pentene & 5 & 3.69 & 5.00 & 0.42 & - \\
\hline 2-Methyl-2-butene & 5 & 0.87 & 1.17 & 0.11 & - \\
\hline 2-Methylpentane & 6 & 11.23 & 11.10 & 3.03 & 0.14 \\
\hline 2-Methyl-1-pentene & 6 & 18.29 & 17.80 & 5.94 & 0.31 \\
\hline 4-Methyl-2-pentene & 6 & 5.51 & 4.98 & 2.22 & 0.11 \\
\hline 2,4-dimethyl-1-pentene & 7 & 3.17 & 2.48 & 2.50 & 0.22 \\
\hline 1,2-Dimethylcyclopentane & 7 & 0.82 & 0.57 & 1.07 & 0.16 \\
\hline 3,5-Dimethylcyclopentene & 7 & 1.05 & 0.84 & 0.82 & 0.05 \\
\hline Toluene & 7 & 0.45 & 0.28 & 1.13 & 0.44 \\
\hline 4-Methylheptane & 8 & 3.03 & 1.82 & 8.70 & 4.47 \\
\hline (E)-4-Methyl-2-heptene & 8 & 0.61 & 0.37 & 1.62 & 0.66 \\
\hline Xylenes & 8 & 0.33 & 0.11 & 1.39 & 1.62 \\
\hline 2,4-Dimethyl-1-heptene & 9 & 6.19 & 3.77 & 24.79 & 30.48 \\
\hline 2,3-Dimethyl-3-heptene & 9 & 0.70 & 0.42 & 2.42 & 2.56 \\
\hline 2,4-Dimethylheptane & 9 & 0.94 & 0.56 & 3.49 & 3.82 \\
\hline 1,3,5-Trimethylcyclohexane & 9 & 1.86 & 1.10 & 7.37 & 11.73 \\
\hline 2,6-Dimethyl-2,4-heptadiene & 9 & 0.25 & 0.09 & 1.10 & 2.02 \\
\hline 2,3-Dimethyl-1,3-heptadiene & 9 & 0.20 & 0.07 & 0.81 & 1.46 \\
\hline 1,3,5-Trimethylbenzene & 9 & 0.11 & 0.07 & 0.64 & 2.03 \\
\hline 3,4-Dimethyl-1-octene & 10 & 0.46 & 0.30 & 2.26 & 4.54 \\
\hline 1,1,3,5-Teteramethylcyclohexane & 10 & - & - & 0.15 & 1.14 \\
\hline 2,6-Dimethylnonane & 11 & 0.17 & 0.18 & 1.46 & 5.42 \\
\hline 2,4-Dimethyl-1-decene & 12 & - & - & 0.29 & 2.72 \\
\hline 4,5-Dimethyl-2-undecene & 13 & - & - & 1.19 & 4.98 \\
\hline
\end{tabular}


Flash point is the legal requirement with regard to the fire hazards of the fuels and which at great extent influences a yield of the final product being manufactured. As the results show (Table 3) hydrocarbons with a number of carbon atoms in a molecule up to 10 have to be removed.

Acid number and particularly total sediment after accelerating ageing are the weakest spots of the product because of significant content of chemically instable olefins and dienes. Acid number even is not constant and increases over time due to oxidation of chemically active hydrocarbons. The ways of the problem solution are intentions of future investigations.

Carbon residue or a tendency to coke formation is determined by molecular mass of the fuel and at the most extent by its chemical composition, i. e., the more arenes in the feed, the faster coke formation during exploitation (fuel burning).

Excellent low temperature properties are the strong side of the liquid product which relates to a high degree of branching and lack of symmetry in chemical structure of the product.

Table 4. Polypropylene thermolysis liquid product conformity with ISO 8217-2012 specification for residual marine fuels

\begin{tabular}{|c|c|c|c|}
\hline \multirow[b]{2}{*}{ Parameter } & \multicolumn{3}{|c|}{ Residual marine fuel } \\
\hline & $\begin{array}{l}\text { ISO-F- } \\
\text { RME } \\
180\end{array}$ & $\begin{array}{l}\text { ISO-F- } \\
\text { RME } \\
380\end{array}$ & $\begin{array}{l}\text { Thermo- } \\
\text { lysis } \\
\text { product }\end{array}$ \\
\hline $\begin{array}{l}\text { Kinematic viscosity } \\
\text { at } 50^{\circ} \mathrm{C}, \mathrm{mm}^{2} / \mathrm{s}\end{array}$ & $\leq 180.0$ & $\leq 380.0$ & 4.044 \\
\hline Density at $15^{\circ} \mathrm{C}, \mathrm{kg} / \mathrm{m}^{3}$ & $\leq 991.0$ & $\leq 991.0$ & 808.0 \\
\hline CCAI & $\leq 860$ & $\leq 870$ & 757 \\
\hline Sulfur content, \%* & $\leq 1.00$ & $\leq 3.50$ & 0.003146 \\
\hline Flash point, ${ }^{\circ} \mathrm{C}$ & $\geq 60.0$ & $\geq 60.0$ & 62.0 \\
\hline Hydrogen sulfide, $\mathrm{mg} / \mathrm{kg}$ & $\leq 2.00$ & $\leq 2.00$ & 0.045 \\
\hline Acid number, mg KOH/g & $\leq 2.5$ & $\leq 2.5$ & 0.23 \\
\hline Total sediment aged, \% & $\leq 0.10$ & $\leq 0.10$ & 0.855 \\
\hline Carbon residue, \% & $\leq 15.00$ & $\leq 18.00$ & 0.061 \\
\hline Pour point, ${ }^{\circ} \mathrm{C}$ & $\leq 30$ & $\leq 30$ & -29 \\
\hline Water content, \% & $\leq 0.50$ & $\leq 0.50$ & 0.14 \\
\hline Ash content, \% & $\leq 0.07$ & $\leq 0.1$ & 0.01 \\
\hline Vanadium, mg/kg & $\leq 150$ & $\leq 350$ & 0.0134 \\
\hline Sodium, $\mathrm{mg} / \mathrm{kg}$ & $\leq 50$ & $\leq 100$ & 4.68 \\
\hline $\begin{array}{l}\text { Aluminum plus silicon, } \\
\mathrm{mg} / \mathrm{kg}\end{array}$ & $\leq 50$ & $\leq 60$ & 45 \\
\hline $\begin{array}{l}\text { Calcium and Zinc or } \\
\text { Calcium and Phosphorus, } \\
\mathrm{mg} / \mathrm{kg}\end{array}$ & $\begin{array}{l}\leq 30 ; \leq 15 \\
\leq 30 ; \leq 15\end{array}$ & $\begin{array}{l}\leq 30 ; \leq 15 \\
\leq 30 ; \leq 15\end{array}$ & $\begin{array}{l}0.058 ; 9.26 \\
0.058 ; 6.04\end{array}$ \\
\hline
\end{tabular}

* after January 1, 2015, sulfur content in marine fuels used at Emission Control Areas (ECA) will be reduced to $0.1 \%$.

Water content in the final product is closely related to refining processes being applied in the manufacture technology and the emulsification capability of the final product. No water or water solutions treatment processes were applied and no natural emulsifies are present in the final product, so water content did not appeared as a problem.

Ash content solely dependent on metal content in the feedstock and surely in the residual liquid product. A set of metals in ISO 8217-2012 specifies petroleum refining residue metals (vanadium trapped in porphyrins) which is chemically very aggressive at a high temperature; dissolved salts (sodium) in dispersed water; Fluid Catalytic Cracking catalyst (aluminum and silicon) trapped in the residual product; as well as prevents application of used lubricating oils that have additives - most often containing calcium, zinc and phosphorus. None of these elements in the residual liquid produced from translucent polypropylene waste were found in amounts bigger then ISO 8217-2012 restricts.

\section{CONCLUSIONS}

1. Thermolysis process experiments proved that only translucent polypropylene waste can be utilized for residual marine fuel production which ash content $(0.01 \%)$ does not exceed ISO 8217-2012 requirements.

2. Standard flash point value of the liquid product can be reached by increasing initial boiling point of the product to $170^{\circ} \mathrm{C}$. That diminishes the yield of the product by $40 \%$.

3. Gas chromatographic analysis of the liquid product shows purely aliphatic, predominantly isomeric composition. More saturated hydrocarbons (over $50 \%$ ) have lighter fractions. The fractions that boil at a temperature of $128^{\circ} \mathrm{C}$ and $160^{\circ} \mathrm{C}$ saturated hydrocarbons compose less than $30 \%$. Aromatic monocyclic hydrocarbons concentrate in heavier distillate fractions, where they make $3.16 \%$ in $128^{\circ} \mathrm{C}$ and $4.09 \%$ in $160^{\circ} \mathrm{C}$ boiling point fractions. The arenes content in fractions BP $30^{\circ} \mathrm{C}$ and $72^{\circ} \mathrm{C}$ is less than $1 \%$.

4. ${ }^{1} \mathrm{H}$ NMR spectrum does not identify aromatic protons in the liquid residual product. Alpha protons of alkyl groups bonded to aromatic rings make $1 \%$. Methyl group protons make $50 \%$ of total in stabilized liquid residue.

5. Applying one pass through thermolytic conversion technology of translucent polypropylene waste there could be produced $24 \%$ (calculating from the feedstock) of residual fuel that meets 15 out of 16 standard requirements for a residual marine fuel.

\section{REFERENCES}

1. López, A., Marco, I., Caballero, B. M., Laresgoiti, M. F., Adrados, A., Torres, A. Pyrolysis of Municipal Plastic Wastes II: Influence of Raw Material Composition under Catalytic Conditions Waste Management 31 2011: pp. $1973-1983$.

2. Ciliz, N. K., Ekinci, E., Snape, C. E. Pyrolysis of Virgin and Waste Polypropylene and Its Mixtures with Waste Polyethylene and Polystyrene Waste Management 24 2004: pp. 173-181.

3. Demirbas, A. Pyrolysis of Municipal Plastic Wastes for Recovery of Gasoline-Range Hydrocarbons Journal of Analytical and Applied Pyrolysis 72 2004: pp. 97-102. http://dx.doi.org/10.1016/j.jaap.2004.03.001

4. Sarker, M., Rashid, M. M., Molla, M. Waste Plastic Conversion into Chemical Product Like Naphtha Journal of Fundamentals of Renewable Energy and Applications 1 2011: pp. 1-6.

5. Panda, A. K., Singh, R. K., Mishra, D. K. Thermolysis of Waste Plastics to Liquid Fuel A Suitable Method for Plastic Waste Management and Manufacture of Value Added 
Products - A World Prospective Renewable and Sustainable Energy Reviews 14 2010: pp. 233-248. http://dx.doi.org/10.1016/j.rser.2009.07.005

6. Plasticeurope, Plastics - the Facts 2012 An Analysis of European Plastics Production, Demand and Waste Data for 2011, Available on: http://www. plasticseurope.org/documents/document/2012112017 0458final_plasticsthefacts_nov2012_en_web_resolution.pdf.

7. Andreikènas, A. Raw Materials 2009, Statistical Publications, 2010: 23 p. (in Lithuanian).

8. Wang, H., $\quad$ Chen, D., Yuan, G., Ma, X., $\quad$ Dai, X. Morphological Characteristics of Waste Polyethylene/ Polypropylene Plastics During Pyrolysis and Representative Morphological Signal Characterizing Pyrolysis Stages Waste Management 33 (2) 2013: pp. 327-339.

9. Yaoa, Z. T., Chenb, T., Lic, H. Y., Xiab, M. S., Yeb, Y., Zheng, H. Mechanical and Thermal Properties of Polypropylene (PP) Composites Filled with Modified Shell Waste Journal of Hazardous Materials 262 2013: pp. $212-217$.

10. Arena, U., Zaccariello, L., Mastellone, M. L. Tar Removal During the Fluidized Bed Gasification of Plastic Waste Waste Management 29 2009: pp. 783-791.

11. Stelmachowski, $\mathbf{M}$. Thermal Conversion of Waste Polyolefins to the Mixture of Hydrocarbons in the Reactor with Molten Metal Bed Energy Conversion and Management 51 2010: pp. 2016-2024.

12. Arabiourrutia, M., Elordi, G., Lopez, G., Borsella, E., Bilbao, J., Olazar, M. Characterization of the Waxes Obtained by the Pyrolysis of Polyolefin Plastics in a Conical Spouted Bed Reactor Journal of Analytical and Applied Pyrolysis 94 2012: pp. 230-237.

13. Stelmachowski, M., Slowinski, K. Thermal and ThermoCatalytic Conversion of Waste Polyolefins to Fuel-Like Mixture of Hydrocarbons Chemical and Process Engineering 33 (1) 2012: pp. 185-198.

14. Jung, S. H., Cho, M. H., Kang, B. S., Kim, J. S. Pyrolysis of a Fraction of Waste Polypropylene and Polyethylene for the Recovery of BTX Aromatics Using a Fluidized Bed Reactor Fuel Processing Technology 91 2010: pp. $277-284$.

15. Kaminsky, W., Predel, M., Sadiki, A. Feedstock Recycling of Polymers by Pyrolysis in a Fluidised Bed Polymer Degradation and Stability 85 2004: pp. 1045-1050.

16. Lin, Y. H., Yen, H. Y. Fluidised Bed Pyrolysis of Polypropylene over Cracking Catalysts for Producing Hydrocarbons Polymer Degradation and Stability 89 2005: pp. $101-108$.

17. Shah, S. H., Khan, Z. M., Raja, I. A., Mahmood, Q., Bhatti, Z. A., Khan, J., Farooq, A., Rashid, N., Wu, D. Low Temperature Conversion of Plastic Waste into Light Hydrocarbons Journal of Hazardous Materials 179 2010: pp. 15-20.

18. Na, J. G., Jeong, B. H., Kim, S. H., Ch., S. S. Pyrolysis of Low-Density Polyethylene Using Synthetic Catalysts
Produced from Fly Ash Journal of Material Cycles and Waste Management 8 2006: pp. 126-132.

19. Park, H. J., Yim, J. H., Jeon, J. K., Kim, J. M., Yoo, K. S., Park, Y. K. Pyrolysis of Polypropylene over Mesoporous MCM-48 Material Journal of Physics and Chemistry of Solids 69 2008: pp. 1125-1128. http://dx.doi.org/10.1016/j.jpcs.2007.10.083

20. Tekin, K., Akalin, M. K., Kadi, C., Karagoz, S. Catalytic Degradation of Waste Polypropylene by Pyrolysis Journal of the Energy Institute 85 (3) 2012: pp. 150-155.

21. Mehrdad, S. A. A., Mehdi, N. H., Yeganeh, H. Evaluation of Pyrolysis Product of Virgin High Density Polyethylene Degradation Using Different Process Parameters in a Stirred Reactor Fuel Processing Technology 109 2013: pp. 90-95.

22. Demirbas, A. Pyrolysis of Municipal Plastic Wastes for Recovery of Gasoline-Range Hydrocarbons Journal of Analytical and Applied Pyrolysis 72 2004: pp. 97-102. http://dx.doi.org/10.1016/j.jaap.2004.03.001

23. Aboulkas, A., Makayssi, T., $\quad$ Bilali, L., $\quad$ Elharfi, K., Nadifiyine, M., Benchanaa, M. Co-Pyrolysis of Oil Shale and Plastics: Influence of Pyrolysis Parameters on the Product Yields Fuel Processing Technology 96 2012: pp. 209-213. http://dx.doi.org/10.1016/j.fuproc.2011.12.001

24. Adrados, A., Marco, I., Caballero, B. M., López, A., Laresgoiti, M. F., Torres, A. Pyrolysis of Plastic Packaging Waste: A Comparison of Plastic Residuals from Material Recovery Facilities with Simulated Plastic Waste Waste Management 32 2012: pp. 826-832.

25. Williams, E. A., Williams, P. T. Analysis of Products Derived from the Fast Pyrolysis of Plastic Waste Journal of Analpical and Applied Pyrolysis 40-41 1997: pp. 347-363.

26. Domınguez, A., Blanco, C. G., Barriocanal, C., Alvarez, R., Diez, M. A. Gas Chromatographic Study of the Volatile Products from Co-Pyrolysis of Coal and Polyethylene Wastes Journal of Chromatography A 918 2001: pp. $135-144$.

27. Singh, S., Wu, Ch., Williams, P. T. Pyrolysis of Waste Materials Using TGA-MS and TGA-FTIR as Complementary Characterisation Techniques Journal of Analytical and Applied Pyrolysis 94 2012: pp. 99-107.

28. Kiran, N., Ekinci, E., Snape, C. E. Recyling of Plastic Wastes via Pyrolysis, Resources Conservation and Recycling 29 2000: pp. 273-283. http://dx.doi.org/10.1016/S0921-3449(00)00052-5

29. Lithuanian Standards Board, LST ISO 8217:2012 Petroleum Products - Fuels (class F) - Specifications of Marine Fuels (ISO 8217:2010, identical).

30. Private conversation with Technical Director of PC Lithuanian Shipping Company.

31. Butkutè, R., Miknius, L. Production of Marine Distillate Fuel Oil from Waste Polypropylene. Chemical Technology 1 (63) 2013: pp. 28 - 33 (in Lithuanian). http://dx.doi.org/10.5755/j01.ct.63.1.4516 